East African Medical Journal Vol. 85 No. 7 July 2008

GENDER-ASSOCIATED VIOLENCE AT A WOMEN'S HOSPITAL IN NAIROBI, KENYA

H. Saidi, BSc (Anat), MBChB, MMed (Surg), FCS (ECSA), Senior Lecturer, K.O. Awori, MBChB, MMed and P. Odula, BSc (Anat), MBChB, MMed (Surg), FCS (ECSA), Department of Human Anatomy, School of Medicine, University of Nairobi, P.O. Box 30197-00100, Nairobi, Kenya

Request for reprints to: Dr. H. Saidi, Department of Human Anatomy, College of Health Sciences, University of Nairobi, P.O. Box 30197-00100, Nairobi, Kenya

\title{
GENDER-ASSOCIATED VIOLENCE AT A WOMEN'S HOSPITAL IN NAIROBI, KENYA
}

\author{
H. SAIDI, K.O. AWORI and P. ODULA
}

\begin{abstract}
Objective: To describe the pattern of gender-associated violence amongst adult survivors. Design: Descriptive case analysis of prospectively collected data.

Setting: The gender violence and recovery centre (GVRC), a shelter and violence treatment facility for the gender-associated violence at the Nairobi Women's hospital (NWH).

Subjects: Data on 663 consecutive adult patients who presented to GVRC between February 2003 and April 2004 were evaluated.

Results: The patients age ranged from 18 to 74 years (mean 27.7 years). Four hundred and eight patients $(61.5 \%)$ presented following sexual assault. Most of assaults were perpetrated at night. A stranger was the assault perpetrator in $75.1 \%$ and $2 \%$ of sexual and non-sexual assault respectively. An intimate partner was the perpetrator in majority (86.5\%) of nonsexual violence. Most physical injuries were minor bruises and swellings. The rate of positive spermatozoa from high vaginal swabs was only $15.9 \%$ in cases of sexual assault. Sexual assault was significantly associated with single status of the victim and assault by more than one assailant.

Conclusions: Violence against women is a common public health problem in the city of Nairobi. Women are vulnerable both in and out of the home. More efforts, including massive public education, are needed to protect this vulnerable population.
\end{abstract}

\section{INTRODUCTION}

Violence against women is a global public health concern. Among college students in the United States of America, $20 \%$ and $25 \%$ of women reported experiencing completed or attempted rape (1). On a wider scale, lifetime partner violence against women is $21 \%$ (2). In Africa, sexual and domestic violence against women is increasingly prevalent. In many parts of the continent however, a lot of the violence perpetrated is kept secret (3); literature of gender violence epidemiology is therefore scarce. Police statistics depict more than 2,500 cases of reported rape in Kenya annually (4). The health consequences of violence, especially sexual abuse, can be significant. Victims suffer physical injuries, psychological disturbances, emotional and social maladjustments.

The gender violence and recovery centre (GVRC) at the Nairobi Womens' hospital provides medical and psychological support to survivors of the violence. It has provided services to 3,128 survivors of sexual abuse between 2002 and $2005(4,5)$. The earlier study provided the admission trends between 2002-2005 and a general evaluation of the programme achievements (5). The current study provides further characteristics of gender-based violence amongst adults presenting at the facility. 


\section{MATERIALS AND METHODS}

Design: This was a descriptive analysis of prospectively collected data on adults surviving physical and sexual violence at a Nairobi violence recovery centre.

Study site: The Nairobi Womens' Hospital (NWH) is a private institution that specialises in obstetrics and gynaecological care but also provides general medical and surgical services. Its gender violence and recovery centre (GVRC) provides free medical and psychological services to survivors of rape and other gender-based violence.

Patients and methods: Demographic information (age, sex, education), event data (place and time of assault), perpetrator relation to victim and clinical data (physical injury, laboratory results) were abstracted from GVRC data capture forms for 663 survivors, 18 years and older, who presented between February 2003 and April 2004. Sexual violence in this context entailed attempted or completed penetration of the anal or genital opening of the victim by the penis. All patients surviving sexual assault were physically examined and investigated for HIV and pregnancy before administration of emergency contraception and prophylactic treatment against sexually transmitted diseases (HIV post-exposure prophylaxis). Findings consistent with completed sex act included perineal bruising and lacerations, hymenal bleeds, abnormally patulous vaginal orifice, anal laxity/dilatation and abnormal vaginal / anal discharges. Findings consistent with physical assault included areas of bruising, abnormal swellings, tenderness, cuts and bleeding.

Statistics: The data were coded and entered for computer analysis using the Statistical Package of Social Sciences (SPSS) for Windows, version 110. Results are presented as means and percentages. Differences observed in the group variables were compared using the univariate analysis. Variables found significant $(\mathrm{p}=0.05)$ were subjected to logistic regression to determine those with the greatest effect.

\section{RESULTS}

Patient characteristics: Six hundred and sixty three patients were analysed. The age range was 18-74 years (mean $27.7 \pm 7.8$ ) with a peak of $31.9 \%$ between 21-30 years of age. Males comprised $2.3 \%$ of the victims.

Sexual violence: The proportion of sexual violence was $61.5 \%$. Majority $(75.1 \%)$ of the assaults were perpetrated by strangers. Intimate partner sexual assault was reported in three survivors $(0.74 \%)$. The number of assailants ranged from one to 20 . The perpetrator acted alone in $70.1 \%$ of cases. Nine per cent of assault cases were perpetrated by groups of three or more assailants (Table 1). The proportion of reported scenes of sexual attack was highest $(55.8 \%)$ for low income residential areas. About one fifth of victims were assaulted outside the city limits (Table 1). Sexual assault was perpetrated in and out of the home in equal proportions ( $46.9 \%$ and $49.7 \%$ of cases respectively). Three quarters of the assaults were committed late in the day between $4 \mathrm{pm}$ and $4 \mathrm{am}$. Majority of the survivors were single $(76.2 \%)$ and educated beyond the elementary level (62.3\%).

Perineal bruising, tears, abnormal discharges, and bleeding were recorded in $240(58.8 \%)$ patients. The commonest documented finding was a whitishclear fluid in the vagina in 120 patients. Sixteen patients had dirty discharges, 35 perineal tears and bruises, 25 bleeding, 13 tender perineums and 20 with fresh hymeneal tears. In three patients the introitus was recorded as gaping while 11 presented with foreign bodies (grass, tampons and condoms) in the vagina. Vaginal swab examination was positive for spermatozoa in $65(15.2 \%)$ cases. Elisa assessment for HIV $1 / 2$ done at presentation was positive for $40(9.8 \%)$ patients.

Associated general body injuries ranged from local swellings to burns and lacerations. Injuries to the head were recorded in $44(10.7 \%)$ patients (bruises 24, tender swellings 14, cuts 6) while signs of neck trauma were recorded in 24 patients (bruises 9 , tender swellings 24 , cuts 1$)$. Thirty four $(8.3 \%)$ patients sustained upper limb injuries (bruises 17 , cuts 3 , burns 1 and tender swellings 13). Back, abdomen and lower limb findings were recorded in 9,32 and 20 patients respectively. There were no fractures or joint dislocations.

Forty six $(11.3 \%)$ patients required specialist reviews and subsequent laparotomy (one case), examination under anaesthesia with or without suturing (10 cases) and surgical debridement and suturing (13 cases). 
Physical violence: The proportion of physical assault was $38.5 \%$. The peak ages for assault victims were $21-$ 30 and 31-40 years of age. The violence perpetrator was an intimate partner in the majority $(86.5 \%)$ of cases. The proportion of assailants unknown to the victim was only $2 \%$ (Table 1 ). The assailant acted alone in all the cases reported. Most patients resided in the poorer sectors of the city $(71.1 \%)$. Majority of the incidents occurred at night (Table 1).

\section{Table 1}

Violence distribution by sex, site, time and perpetrator characteristic

\begin{tabular}{|c|c|c|c|c|}
\hline \multirow[t]{2}{*}{ Variable } & \multicolumn{2}{|c|}{ Physical assault } & \multicolumn{2}{|c|}{ Sexual assault } \\
\hline & No. & $(\%)$ & No. & $(\%)$ \\
\hline \multicolumn{5}{|l|}{ Gender } \\
\hline Female & 252 & 98.8 & 396 & 97.1 \\
\hline Male & 3 & 1.2 & 12 & 2.9 \\
\hline \multicolumn{5}{|l|}{ Perpetrator } \\
\hline Intimate partner & 217 & 86.5 & 3 & 0.74 \\
\hline Close relative & 13 & 5.2 & 5 & 1.24 \\
\hline Neighbour & 2 & 0.8 & 23 & 5.7 \\
\hline Unspecified/known & 14 & 5.6 & 69 & 17.2 \\
\hline Unknown/other & 5 & 2.0 & 302 & 75.1 \\
\hline \multicolumn{5}{|l|}{ Age (years) } \\
\hline $18-20$ & 23 & 9.1 & 112 & 27.5 \\
\hline $21-30$ & 118 & 46.3 & 199 & 48.8 \\
\hline $31-40$ & 90 & 35.3 & 78 & 19.1 \\
\hline $41-50$ & 20 & 7.8 & 16 & 39.2 \\
\hline $51+$ & 4 & 1.6 & 3 & 0.7 \\
\hline \multicolumn{5}{|l|}{ Time of occurence } \\
\hline 4-7.59 am & 25 & 10.6 & 37 & 9.4 \\
\hline $8-11.59 \mathrm{am}$ & 23 & 9.8 & 22 & 5.7 \\
\hline $12-3.59 \mathrm{pm}$ & 15 & 6.4 & 39 & 10.2 \\
\hline $4-7.59 \mathrm{pm}$ & 39 & 16.6 & 72 & 18.8 \\
\hline $8-11.59 \mathrm{pm}$ & 85 & 36.2 & 122 & 31.8 \\
\hline $12-3.59 \mathrm{am}$ & 48 & 20.4 & 92 & 24.0 \\
\hline \multicolumn{5}{|l|}{ Education level } \\
\hline Primary / Elementary & 62 & 26.8 & 138 & 36.1 \\
\hline High school & 82 & 35.5 & 147 & 38.5 \\
\hline College/University & 83 & 35.9 & 91 & 23.8 \\
\hline Nil & 4 & 1.7 & 6 & 1.6 \\
\hline \multicolumn{5}{|l|}{ Number of perpetrator(s) } \\
\hline One & 248 & 100 & 283 & 70.4 \\
\hline Two & 0 & & 53 & 13.2 \\
\hline Three or more & 0 & & 66 & 16.5 \\
\hline \multicolumn{5}{|l|}{ Scene } \\
\hline Slum/informal & 20 & 22.2 & 52 & 14.6 \\
\hline High density estate & 44 & 48.9 & 147 & 41.2 \\
\hline Low density estate & 15 & 16.7 & 57 & 16.0 \\
\hline City centre & 3 & 3.3 & 22 & 6.2 \\
\hline Peri-urban & 8 & 8.9 & 79 & 22.1 \\
\hline
\end{tabular}


The victims were mostly educated beyond elementary school $(71.4 \%)$ and married $(72.3 \%)$. Quarrels over infidelity, family finances and children were the most common determinate causes (58.0\%) for intimate partner violence. Alcohol was a contributing factor in $10.1 \%$ of determinate cases.

One hundred and fifty patients $(58.8 \%)$ sustained injuries to the head. The commonest injury types were bruises and areas of tenderness documented in 65 and 75 patients respectively. There were 10 cuts on the head. Sixty nine patients sustained injuries to the neck (bruises 23 cases, cuts 3 cases, tender areas 42 cases, burn 1 case). The number of patients with injuries distributed to the upper limbs, chest, back and abdomen was 87, 59, 56 and 23 respectively.

When the violence groups were compared using univariate analysis, factors significantly associated with sexual violence included residence in a poor neighborhood $(\mathrm{p}=0.006)$, perpetration by a stranger $(p<0.001)$, perpetration by multiple assailants $(P=0.001)$, unmarried status $(\mathrm{p}<0.001)$, and younger age. Sexual and physical assaults did not differ with regard to time of day of occurrence (Table 2). Logistic regression showed perpetration by a stranger, perpetration by multiple assailants, single marital status and age less than 20 years to be independently associated with sexual violence (Table 4).

Compared toadolescentviolence(19-20yearsage), adult violence was more physical ( $\mathrm{p}<0.001, \mathrm{OR} 6.7, \mathrm{CI}$ 4.2-10.6), occurred later in the day ( $\mathrm{p}<0.001, \mathrm{OR} 2.2, \mathrm{CI}$ 1.6-3.1) and with a higher female gender proportion $(p=0.017)$. Adult and adolescent violence were similar for perpetrator characteristics and scene of attack (Table 3). On logistic regression, single marital status and sexual violence were significant (Table 4).

Table 2

Comparison of sexual and non-sexual violence

\begin{tabular}{lccc}
\hline Characteristic & Physical violence & Sexual assault & P-value \\
\hline Gender & 252 & 396 & \\
Female & 3 & 12 & 0.137 \\
Male & & & \\
Time of occurence & 77 & 133 & 0.634 \\
Day & 158 & 251 & \\
Night & & & $<0.001$ \\
Marital status & 42 & 301 & \\
Single & 180 & 71 & 0.006 \\
Married & & & \\
Neighborhood & 64 & 199 & $<0.001$ \\
Poor/dense & 25 & 158 & \\
Affluent & & & $<0.001$ \\
Number of assailants & 248 & 283 & \\
1 & 0 & 119 & \\
$>1$ & & 100 & \\
Assailant character & 246 & 302 & \\
Known/intimate & 5 & & \\
Stranger & & & \\
& & &
\end{tabular}




\section{Table 3}

Univariate analysis comparing adolescent and adult violence

\begin{tabular}{|c|c|c|c|c|c|c|}
\hline Variable & \multicolumn{2}{|c|}{ Adolescents $(\mathrm{n}=70)$} & \multicolumn{2}{|c|}{ Adults $(n=593)$} & $\mathrm{P}$-value & OR (CI) \\
\hline \multicolumn{7}{|l|}{ Gender } \\
\hline Female & 65 & 92.9 & 583 & 98.3 & 0.04 & $1.4(0.9-1.9)$ \\
\hline Male & 5 & 7.1 & 10 & 1.7 & & \\
\hline \multicolumn{7}{|l|}{ Perpetrator } \\
\hline Known & 21 & 30.4 & 325 & 55.5 & $<0.001$ & $1.1(1.0-1.2)$ \\
\hline Stranger & 48 & 69.6 & 260 & 44.5 & & \\
\hline \multicolumn{7}{|l|}{ Assault } \\
\hline Sexual & 60 & 85.7 & 348 & 58.7 & $<0.001$ & $1.4(0.87-1.34)$ \\
\hline Physical & 10 & 14.3 & 245 & 41.3 & & \\
\hline \multicolumn{7}{|l|}{ Time } \\
\hline 8-8 pm & 27 & 40.9 & 183 & 33.0 & 0.171 & $0.96(0.9-1.0)$ \\
\hline 8-8 am & 39 & 59.1 & 99 & 67.0 & & \\
\hline \multicolumn{7}{|l|}{ Perpetrator } \\
\hline Single & 50 & 71.4 & 482 & 83.1 & 0.007 & $1.1(1.0-1.2)$ \\
\hline Multiple & 20 & 28.6 & 98 & 17.9 & & \\
\hline \multicolumn{7}{|l|}{ Scene } \\
\hline High density & 36 & 63.2 & 228 & 58.5 & 0.566 & $0.97(0.9-1.0)$ \\
\hline Up-market & 21 & 36.8 & 162 & 41.5 & & \\
\hline \multicolumn{7}{|l|}{ Status } \\
\hline Unmarried & 55 & 78.5 & 288 & 54.4 & $<0.001$ & $4.0(2.3-9.3)$ \\
\hline Married & 10 & 21.5 & 241 & 45.6 & & \\
\hline
\end{tabular}

$\mathrm{OR}=$ odds ratio, $\mathrm{CI}=95 \%$ confidence interval No. $=$ number

Table 4

Logistic regression analysis to determine independent factors associated with adolescent vs adult violence and sexual versus non-sexual violence

\begin{tabular}{lll}
\hline Independent factor & P-value & P-value \\
& Sexual vs. non-sexual violence & Adolescent vs. adult violence \\
\hline Gender & 0.183 & 0.931 \\
Time of day & 0.766 & 0.024 \\
Number of assailants & $<0.001$ & 0.379 \\
Assailant known & $<0.001$ & 0.156 \\
Marital status & $<0.001$ & $<0.001$ \\
Scene of assault & 0.095 & 0.630 \\
Age $>20$ years & $<0.045$ & $\mathrm{~N} / \mathrm{A}$ \\
Type of violence & $\mathrm{N} / \mathrm{A}$ & 0.003 \\
\hline
\end{tabular}




\section{DISCUSSION}

This study presents one of the few reports of gender-based violence from Kenya $(5,6)$. Majority $(61.5 \%)$ of the victims were sexually assaulted. The establishment of the recovery centre with dedicated staff to cater for survivors has likely encouraged many victims to come out of the silence of abuse and seek treatment. But, if communities continue to ignore this as a crime, family conflicts discourage reporting, and the association of violence acts with stigma and cultural sensitivity persists, the true picture and magnitude will remain unclear. Under-reporting of gender-based violence is a global concern. In the USA in 2002 for example, only 39\% of rapes and sexual assaults were reported to law enforcement officials (7). In South Africa, a nine-fold difference was reported between the cases reported to police and those reported in a representative community based survey (3).

The results on physical violence are important in a number of ways. The intimate partner was the predominant perpetrator. The Kenyan society is largely patriarchal where the husband is the head of the household with women having little influence in decisions affecting their lives. Wife-beating is considered a normal part of a marriage relationship. This is similar to the picture from the continent. In a Nigerian study of civil servants, the prevalence of wife-beating was $31.3 \%$ (8). In rural Uganda, $30 \%$ of women experience physical abuse from their current partners (9). A Zimbabwean study was worrying in the sense that half of women surveyed believed that wife beating was justified if she argued with her spouse, neglected her children, or went out without permission (10). The rural Ugandan study had similar perceptions (9).

Partner sexual violence was reported in less than one per cent of the victims in the current study. Many women would not consider forced intercourse experienced with their partners as rape. Further, the Kenyan Penal Code does not recognise marital rape as a criminal offence (4) because of the presumption, especially in customary law, that consent to sexual intercourse is given by the act of marriage. The majority of women would therefore not mention forced sex in the home even when seeking medical attention for other injuries. In a South African survey, young women reported that forced intercourse with their partners could never be termed as rape because "it is with your boyfriend and there is something between you" (11). Public education on genderrelated violence would be key in having more survivors of gender-related violence reporting.

In the present study, majority of the victims resided in the low-income settlements within the city. This finding is consistent with literature. Reported risk factors for partner violence include the economic status of the male partner, low level of education, perceiving hitting women to be acceptable and problem of alcohol use $(1,9,12)$. In China, provinces with a booming economy reported less cases of partner violence. Almost half of women whose partners were of low socioeconomic status had ever been hit, compared with about a quarter of women whose partner was of high status (2). In Uganda, women whose partner frequently or always consumed alcohol before sex faced risks of domestic violence almost five times higher than those whose partners never drank before sex (9). Interventions aimed at improving the community socioeconomic well being and that of reducing alcohol consumption may benefit the vulnerable women.

Several patterns in the data we have presented are inconsistent with the existing literature. Our data indicate that majority of female victims $(75.1 \%)$ were sexually assaulted by people unknown to them. Further, two thirds of survivors for both sexual and non-sexual violence were educated beyond the elementary level with significant proportion beyond high school. A study of the urban population of Toronto showed two-thirds of sexual assault was committed by people known to the victims (13). In the study by Tjaden and Toennes (14), $64 \%$ of women and $16 \%$ of men who reported sexual violence were raped, physically assaulted or stalked by an intimate partner. Earlier studies have shown that women with a high status as measured by their educational attainment are more protected from the risk of partner violence (9). Our study results attest to the acknowledged view that violence against women pervades all social and ethnic groups. Although the risk was highest for high density low income neighbourhoods, women with university/tertiary education, in affluent areas, in the city centre streets and outside the city limits were sexually accosted in $23.8 \%, 16.0 \%, 6.2 \%$ and $22.1 \%$ of the cases respectively. A concerted societal action is required to stem it. 
The result on gang rape is similar to other reports from Africa. A Johannesburg surveillance cited by Abrahams (15) reported that more than one third of women reported being raped by more than one perpetrator. We did not examine the circumstances associated with gang rape in this series. Elsewhere, the activity is associated with forceful abduction and "stream-lining" $(11,15)$. In the latter, the assailants are often young and known to the victim.

A number of observations regarding violence characteristics in adolescents and adult women are interesting. The younger woman was more likely to be sexually assaulted while assaults on men were encountered with a higher frequency among the younger survivors. The data on marital status and involvement in sexual assault is likely a proxy for the age variable. Published literature also suggests young women are at higher risk of being raped than older women (16). In South Africa, the period of greatest risk of rape is in the second decade with both girls and boys vulnerable. During this time, male relatives, boyfriends, men in positions of power and other children form the body of sexual abusers (17). Public health campaigns to protect younger persons as well as legal efficient frameworks are needed to convict those assailing adolescent youth.

General body trauma was found in a large proportion of survivors of sexual assault victims. In Uganda, extra-genital injuries were reported in $19.0 \%$ of 58 sexually assaulted females (18). In France, Grossin et al (19) documented $39.1 \%$ of 418 cases of sexual assault had associated general body trauma. Higher rates of general body trauma $(67 \%)$ have been reported in Canada and the United states $(13,20)$. It is suggested that physicians caring for victims of rape should always examine for and record these injuries. In a minor proportion of cases they may need surgical intervention. About 5\% of patients in the current series needed surgical and gynaecological consultations for the injuries sustained.

Detection of spermatozoa was only $15.2 \%$ in the current study. In the account by Grossin et al (19) this rate was $30.3 \%$. There is data to show that the sperm detection rates are higher when the crime laboratory is involved. In an account of 1,076 sexual assault cases by Riggs et al (20), sperms were noted in the emergency department (ED) wet mount in only $13 \%$ (93/716) of the victims. Combination of ED sperm data and crime laboratory semen data evidence of sperm and semen were found in $48 \%$ of cases (20).
Our results are significant in as far as evidence of rape under Kenyan law can only be obtained by examination of semen deposits, bruises and laceration. Semen deposits, bruises and perineal lacerations were recorded in $58.8 \%$ of survivors in this study. Absence of this kind of evidence renders the prosecution's case more difficult to prove. Many cases get dismissed because of lack of corraboration. It is important therefore that health professionals taking care of survivors of rape have the necessary skill to adequately document these examination findings as medical evidence for trial purposes. The Nairobi womens' GVRC can play a lead role in championing this aspect of survivor care.

In conclusion, intimate partner dynamics are largely similar to those of the rest of the world. Public education and an improved socioeconomic environment may encourage more survivors to seek assistance. The true prevalence of spousal violence including marital rape remains unknown.

Implications for prevention: Sexual violence is commonest amongst younger females. Schools may form an important entry point for public education where the girl is empowered with the knowledge of her vulnerability. The predominant intimate partner contribution to non-sexual violence attests to the patriarchal nature of our society. Many women tend to accept wife-beating as the norm. The Nairobi womens' hospital and other civil society should continue advocating for the rights of the woman. Further, there is need to insist that laws protect female spouses and punish those who discipline their partners through physical violence. The characteristics of the assailant and the environment of the assault need to be further defined to enable the institution of specific preventive and control strategies.

The following were noted from our study:

(i) The intimate partner was the reported assailant in $86.5 \%$ of non-sexual assaults while the stranger accounted for three quarters of sexual assaults.

(ii) Women were assaulted both at home and away in equal proportions.

(iii) The peak age for sexual assault was the second and third decade while that for non-sexual assault was the third and fourth decades.

(iv) Most reported gender-related assaults occur in low-income residential neighbourhoods of Nairobi. 


\section{ACKNOWLEDGEMENT}

To the management of Nairobi Women Hospital for permission to carry out the study.

\section{REFERENCES}

1. Fischer, B.S., Cullen, F.T. and Turner, M.G. The sexual victimization of college women. Washington: Department of Justice (US), National Institute of Justice 2000. Publication No. NCJ 182369.

2. Parish, W., Wang, T., Laumaun, E.O., et al. Intimate partner violence in China: National prevalence, risk factors and associated health problems. Int. Family Planning Perspectives. 2004; 30: 174-181.

3. Jewkes, R. and Abrahams, $N$. The epidemiology of rape and sexual coercion in South Africa: An overview. Soc. Sci. Med. 2002; 47: 233-242.

4. Reuters Alertnet-Kenya: Sexual and domestic violence prevalent. 27, Oct 2005. http://www.alertnet.org.

5. Thenya, S., Gichangi, P. and Kiama, L. Gender based violence and sexual violence: three years experience of Nairobi Womens hospital. J. Obstet. Gynecol. East Cent. Afr. 2006; 19: 8-20.

6. Gathece, L., Gichangi, P., Thenya, S., et al. Prevalence of domestic violence among clients seeking emergency department services in a private hospital, Nairobi, Kenya. J. Obstet. Gynecol. East Cent. Afr. 2004; 17: 8-17.

7. Department of Justice. Criminal victimization 2002. Washington: Government printing office; 2003. Publication No. NCJ 199994. www.ojp.usdoj.gov/bjs/ pub/pdf/cv02.pdf.

8. Fawole, O.I., Aderonmu, A.L. and Fawole, A.O. Intimate partner abuse: Wife beating among civil servants in Ibadan, Nigeria. Afr. J. Reprod. Health. 2005; 9: 54-64.

9. Koenig, M.A., Lutalo, T., Zhao, F., et al. Domestic violence in rural Uganda: evidence from a communitybased study. Bull. WHO. 81:
10. Hindin, M.J. Understanding women's attitudes towards wife beating in Zimbabwe. Bull. WHO. 2003; 81: 501-508

11. Wood, K. and Jewkes, R. Dangerous love: Reflections on violence in sexual relationships of young people in Imtata. In: R. Morrell (Ed), Changing men in South Africa. Pietermaritzburg: University of Natal Press. 2001; 317-336.

12. Abrahams, N., Jewkes, R., Laubscher, R., et al. Intimate partner violence: prevalence and risk factors for men in Cape Town, South Africa. Violence Vict. 2006; 21: 247-264.

13. Stermac, L.E., Du Mont J.A. and Kalemba, V. Comparisson of sexual assaults by strangers and known assailants in an urban population of women. CMAJ. 1995; 153: 1089-1094.

14. Tjaden, P. and Thoenness, N. Prevalence, incidence and consequences of violence against women. Findings from the National Violence Against Women Survey. Washington, DC: U.S. Department of Justice and Center for Disease Control and Prevention. 1998.

15. Abrahams, N. Sexual violence against women in South Africa. Sexuality in Africa. 2004; 1: 1-4.

16. Acierno, R., Resnick, H., Kilpatrick, D.G., et al. Risk factors for rape, physical assault, and post-traumatic stress disorder in women: examination of differential multivariate relationships. J. Anxiety Disorders. 1999; 13: $541-563$

17. Jewkes, R., Levin, J., et al. Rape of girls in South Africa. Lancet. 2002; 359: 319-320.

18. Ononge, S., Wandabwa, J., Kiondo, P., et al. Clinical presentation and management of alleged sexually females at Mulago hospital, Kampala, Uganda. Afr. Health Sci. 2005; 5: 50-54.

19. Grossin, C., Sibille, I., Lorin de la Grandmaison, G., et al. Analysis of 418 cases of sexual assault. Forensic Sci. Int. 2003; 131: 125-130.

20. Riggs, N., Houry, D., Long, G., et al. Analysis of 1,076 cases of sexual assault. Ann. Med. 2000; 35: 358-362. 